Original Article

\title{
Volatile oil of Croton zehntneri per oral sub-acute treatment offers small toxicity: perspective of therapeutic use
}

\author{
Andrelina N. Coelho-de-Souza ${ }^{a}$, , Maria Valdenir A.P. Rocha ${ }^{a}$, Keciany A. Oliveira ${ }^{a}$, \\ Yuri A.G. Vasconcelos a , Edgleyson C. Santos ${ }^{a}$, Kerly Shamyra Silva-Alves ${ }^{a}$, Lúcio Ricardo L. Diniz ${ }^{\text {, }}$, \\ Francisco Walber Ferreira-da-Silva ${ }^{c}$, Ariclécio C. Oliveira ${ }^{a}$, Edson L. Ponte ${ }^{d}$, \\ Janaína Serra-Azul M. Evangelista ${ }^{a}$, Ana Maria S. Assreuy ${ }^{a}$, José Henrique Leal-Cardoso a \\ a Instituto Superior de Ciências Biomédicas, Universidade Estadual do Ceará, Fortaleza, CE, Brazil \\ b Departamento de Morfologia, Universidade Federal de Aracaju, Aracaju, SE, Brazil \\ ' Universidade Estadual do Vale do Acaraú, Sobral, CE, Brazil \\ d Centro Universitário Christus, Campus do Parque Ecológico, Fortaleza, CE, Brazil
}

\section{A R T I C L E I N F O}

\section{Article history:}

Received 22 March 2018

Accepted 21 November 2018

Available online 19 December 2018

\section{Keywords:}

Anethole

Volatile oil

Euphorbiaceae

Toxicity

\begin{abstract}
A B S T R A C T
Croton zehntneri Pax \& K. Hoffm., Euphorbiaceae, or “canela-de-cunhé” is used in the Northeast Brazil to treat several diseases. Leaves and aerial parts of $C$. zehntneri are rich in volatile oil of high potential therapeutic. This study aimed to investigate volatile oil systemic toxicity after per oral treatment in rats. Volatile oil characterization (gas chromatography and mass spectrometry) showed $85.7 \%$ anethole and $4.8 \%$ estragole. Male Wistar rats (116-149 g) were treated with volatile oil (250 mg/kg p.o.) during ten weeks and evaluated for the following parameters: survival; food and water intake; body mass; absolute/relative organs weight; hemogram; plasma biochemical dosage; organs morphology. Volatile oil did not alter animal water and food consumption or the relative/absolute weight of most organs, but animals gained less weight. Volatile oil did not alter function biomarkers of pancreas, kidney, heart or liver, but increased plasma gamma-glutamyltranspeptidase (liver biomarker) and decreased uric acid (kidney biomarker). Although volatile oil had caused discrete morphological alterations in some organs, it did not induce architectural changes in these organs. In conclusion, the sub-acute per oral treatment with volatile oil no longer than ten weeks in rats offers small toxicity at doses below $250 \mathrm{mg} / \mathrm{kg}$.

(C) 2018 Sociedade Brasileira de Farmacognosia. Published by Elsevier Editora Ltda. This is an open access article under the CC BY-NC-ND license (http://creativecommons.org/licenses/by-nc-nd/4.0/).
\end{abstract}

\section{Introduction}

Croton zehntneri Pax \& K. Hoffm., Euphorbiaceae, is a plant native to Northeast Brazil, where it is popularly known as "canela-decunha". Its barks and leaves are widely used as infusions and teas to stimulate appetite and to treat inflammation, colic, diarrhea, nervous (anxiety, insomnia, irritability) and gastrointestinal disorders (Leal-Cardoso and Fonteles, 1999; Coelho-de-Souza et al., 2013). Popular sellers also prepare tea from C. zehntneri leaves to treat rheumatic, cardiac and respiratory diseases and other parts in decoctions and cataplasmas to treat inflammation and wound healing (Cavalcanti et al., 2012). Leaves and aerial parts of C. zehntneri are rich in volatile oil of pleasant aroma, resembling that

\footnotetext{
* Corresponding author.

E-mail: andrelina.noronha@uece.br (A.N. Coelho-de-Souza).
}

of anise (Illicium verum) (Craveiro et al., 1977; Leal-Cardoso and Fonteles, 1999). The volatile oil of $C$. zehntneri (EOCz) is composed by several terpenes, terpenoids and phenylpropanoids, including trans-anethole (85.7\%) and estragole (Craveiro et al., 1977).

Volatile oil has several biological and pharmacological effects, such as central nervous system depression (Batatinha et al., 1995; Lazarini et al., 2000), blockade of neuromuscular transmission (Albuquerque et al., 1995), antispasmodic (Coelho-de-Souza et al., 1997, 1998), antinociceptive (Oliveira et al., 2001), gastroprotective (Coelho-de-Souza et al., 2013), healing (Cavalcanti et al., 2012) and cardiovascular (de Siqueira et al., 2006). Other effects had also been described for EOCz, including anti-helmintic (Camurça-Vasconcelos et al., 2007), bactericidal (Andrade et al., 2015), antifungal (Fontenelle et al., 2008), hepatoprotective (Lima et al., 2008) and larvicidal (against Aedes aegypti) (Morais et al., 2006). Some of these effects have being assigned to trans-anethole, the main constituent of EOCZ. Several studies demonstrated that 
trans-anethole exhibits antioxidant (Galicka et al., 2014), antibacterial (Zahid et al., 2015), anticancer (Chen and de Graffenried, 2012; Choo et al., 2011), antigenotoxic (Newberne et al., 1999), antiplatelet (Tognolini et al., 2007) and anti-inflammatory properties (Ponte et al., 2012; Ritter et al., 2017).

Acute studies have shown that EOCz (Oliveira et al., 2001) and trans-anethole (Newberne et al., 1999; Ponte et al., 2012) exhibit low toxicity. EOCz administered by oral route presents wide therapeutic window $\left(\mathrm{LD}_{50}>2.5 \mathrm{~g} / \mathrm{kg}\right.$ ) (Oliveira et al., 2001), since most of its pharmacological effects are manifested at doses between 0.03 and $0.3 \mathrm{~g} / \mathrm{kg}$. Moreover, according to Food and Drug Administration, trans-anethole is considered safe and devoid of genotoxic and carcinogenic effects (Newberne et al., 1999). However, toxicity studies performed for longer treatment periods (10-week period) are necessary to validate the consumption of both $C$. zehntneri and EOCz.

Based in the popular use of $C$. zehntneri and in the pharmacological effects of EOCz, this study aimed to investigate EOCz toxicity after per oral treatment in rats along ten weeks.

\section{Material and methods}

\section{Plant material, extraction and EOCz chemical analysis}

Croton zehntneri Pax \& K. Hoffm., Euphorbiaceae, leaves were collected in the small village of Cocalzinho, near to the city of Viçosa do Ceará (Ceara State, Brazil) and its identification was confirmed by Dr. F.J. Abreu Matos (Laboratory of Natural Products, Federal University of Ceara-UFC, Fortaleza, CE, Brazil). A voucher specimen (no. 277477) has been deposited at the herbarium Prisco Viana of the Federal University of Ceara (UFC). EOCz was obtained by steam distillation and its chemical constituents (trans-anethole: $85.7 \%$, estragole: $4.8 \%$, 1,8 -cineole: $2.95 \%$, $\beta$-myrcene: $2.2 \%$, anisaldehyde: $1.22 \%$, trans-caryophyllene: $0.9 \%$, unidentified: $2.23 \%$ ) were determined by gas chromatography coupled to mass spectrometry in the Technological Development Park of the Federal University of Ceará - PADETEC (Technological Development Park)/UFC. The analysis conditions were as following: Hewlett-Packard 6971 (Palo alto, CA, USA); column of dimethylpolysiloxane DB-1 fused silica capillary column $(30 \mathrm{~m} \times 0.25 \mathrm{~mm} ; 0.1 \mu \mathrm{m})$; helium $(1 \mathrm{ml} / \mathrm{min})$ as carrier gas; injector temperature: $250^{\circ} \mathrm{C}$; detector temperature: $200^{\circ} \mathrm{C}$; column temperature: $35-180^{\circ} \mathrm{C}$ at $4{ }^{\circ} \mathrm{C} / \mathrm{min}$ and $180-250^{\circ} \mathrm{C}$ at $10^{\circ} \mathrm{C} / \mathrm{min}$; and mass spectra: electronic impact $70 \mathrm{eV}$. The compounds were identified using mass spectral library search.

\section{Animals}

Male Wistar rats $(n=30)$ of the Central Animal House/UFC, presenting initial body mass that ranged from 116-149g, were randomly distributed to collective cages (five per cage). Rats were chosen for this study, since they are considered the most conservative model to evaluate hepatotoxicity of terpenes in humans (Newberne et al., 1999). Before treatment, animals were maintained for 14 days in the Experimental Physiology Laboratory-UECE at $23 \pm 2{ }^{\circ} \mathrm{C}, 12$-h light/dark cycle. Standard rodent chow (BioBaseBio-TEC) and water were available ad libitum. The general animal appearance was observed daily for disease detection, and weekly for the analysis of parasites in feces samples.

\section{Experimental design}

Volatile oil or trans-anethole (1-methoxy-4-[(E)-prop-1-enyl] benzene) (Sigma-Aldrich, St. Louis, MO, EUA) was mixed with water daily prior to animal administration. Rats ( $n=10$ /group) received $250 \mathrm{mg} / \mathrm{kg} \mathrm{EOCz}$ (p.o.) or trans-anethole (used as the reference drug) for 10 weeks. The effective dose of $250 \mathrm{mg} / \mathrm{kg}$ (body mass) was selected since it is lower than $10 \%$ of EOCz LD50 (Oliveira et al., 2001). The control group received water by gavage in equivalent volume. During treatment, animals were weighted weekly and the food and water intake were daily measured by subtracting the amount measured from the amount offered at a given cage, after $24 \mathrm{~h}$ of consumption, and dividing the result by the number of animals in each cage (five animals).

Protocols were approved by the Ethical Committee (CEUA-UECE no. 06379067-0).

After treatment, animals were anesthetized with xylazine $(10 \mathrm{mg} / \mathrm{kg}$ ) and ketamine $(75 \mathrm{mg} / \mathrm{kg})$, and blood was collected for hematological and clinical chemistry analysis. Blood samples were collected in tubes containing potassium EDTA for hematological evaluation (automated equipment Pentra $60^{\circledR}$ ) of the following parameters: erythrocyte, leukocyte and platelet counts; hematocrit (Ht); hemoglobin ( $\mathrm{Hb})$; mean corpuscular volume (MCV); mean corpuscular hemoglobin (MCH); hemoglobin mean concentration (MCHC) and red distribution width (RDW). The morphological analysis of blood cells and the differential leukocyte counts were performed on smears stained with fast panoptic dye $\left(\right.$ Laborclin $\left.^{\circledR}\right)$. For the clinical chemistry analysis, blood samples were collected in tubes containing separator gel and left to clot retraction. Samples were centrifuged and the serum analyzed (Diagnostic Labtest S.A., 2009) in automated equipment (Labmax $240^{\circledR}$ ) for the following parameters: amylase, lipase, aspartate aminotransferase (AST), alanine aminotransferase (ALT), alkaline phosphatase (AP), lactate dehydrogenase (LDH), gamma-glutamyltranspeptidase (GAMA-GT), total creatine kinase (CK-NAC), creatine kinase isoenzyme $\mathrm{MB}$ (CK-MB), total bilirubin (TB), direct and indirect bilirubin (DB, IB), total proteins (TP), albumin and globulin.

Animals were euthanized for histological analysis of liver, lung, adrenal gland, spleen, stomach, duodenum, cerebral cortex and heart. The organs were removed, weighed, fixed during $24 \mathrm{~h}$ in $10 \%$ buffered formaldehyde, transferred to $70 \%$ ethanol, trimmed using an automated histotechnique (Leica ${ }^{\circledR}$ ), embedded in paraffin, sectioned to a thickness of 3-5 $\mu \mathrm{m}$ and stained with hematoxilin and eosin (H\&E). The analysis was performed in a double-blind fashion manner. The photomicrographs were performed by the use of Microscope Nikon Eclipse Nis and Software Nis 4.0 .

\section{Statistical analysis}

The results were presented as mean \pm S.E.M. and analyzed by one-way ANOVA followed by Bonferroni or Student-Newman-Keuls Method. $p \leq 0.05$ was considered significant.

\section{Results}

Survival, body mass, absolute and relative organs weight and food and water intake of rats treated with EOCZ

Similar to trans-anethole, rats treated with EOCz $(250 \mathrm{mg} / \mathrm{kg}$; p.o.) during ten weeks survived until the end of the experiment (Table 1). Besides, the treatment did not alter the animal water consumption, except at the fifth week, in which $\mathrm{EOCz}$ induced a discrete increase (Fig. 1A), but gained less weight (15-16\%) compared to control (Table 1). Accordingly, the treatment with EOCz, as with anethole, exhibited small, but significant reduction in food intake from week 8 to week 10 , reducing by $12 \%$ at week 10 (EOCz: $187.00 \pm 1.90 \mathrm{~g}$ vs. control: $210.0 \pm 3.98 \mathrm{~g}$ ) (Fig. 1B). In 
Table 1

Survival and body mass of rats after 10 week-treatment with volatile oil of Croton zehntneri or anethole.

\begin{tabular}{|c|c|c|c|c|c|}
\hline \multirow[t]{2}{*}{ Treatment } & \multirow[t]{2}{*}{ Survival } & \multicolumn{3}{|c|}{ Body mass (g) } & \multirow[t]{2}{*}{ Final body mass gain (\% of control) } \\
\hline & & Initial & Final & Body mass gain & \\
\hline Control & $10 / 10$ & ${ }^{\mathrm{b}} 163.2 \pm 4.97$ & $384.8 \pm 9.48$ & $221.6 \pm 5.85$ & 100.00 \\
\hline${ }^{\mathrm{a}} \mathrm{EOCZ}$ & $10 / 10$ & $175.6 \pm 4.66$ & $364.0 \pm 8.00$ & $188.4 \pm 8.11^{c}$ & 94.59 \\
\hline Anethole & $10 / 10$ & $177.1 \pm 2.97$ & $362.5 \pm 8.71$ & $185.4 \pm 8.03^{c}$ & 94.20 \\
\hline
\end{tabular}

a $\mathrm{EOCz}$, volatile oil of $C$. zethneri.

b Mean \pm S.E.M.

c $p \leq 0.05$ vs. control (ANOVA and Student's $t$-test).

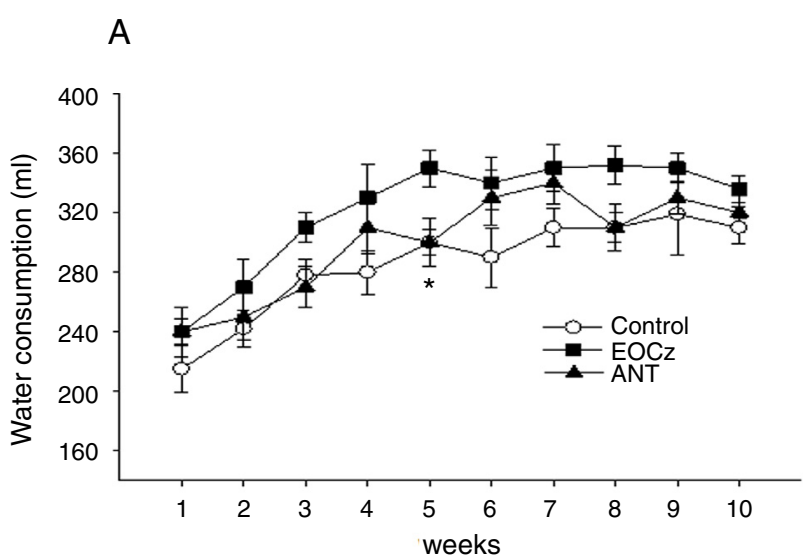

B

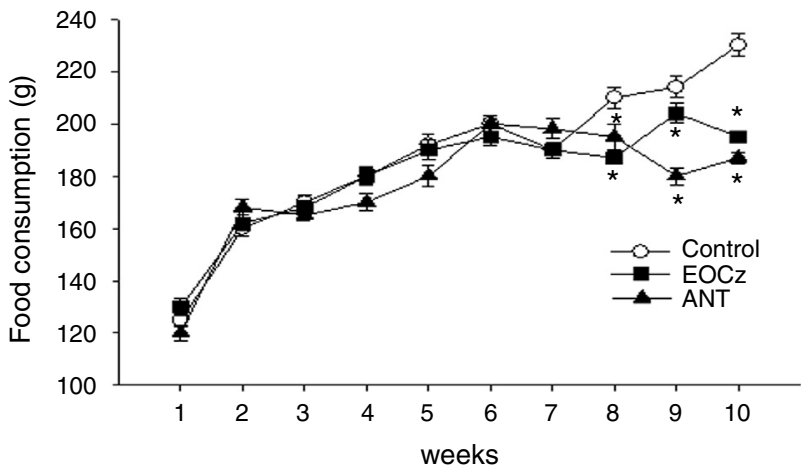

Fig. 1. Water (A) and food (B) consumption of rats treated with volatile oil of Croton zehntneri. Animals received water, anethole or volatile oil at $250 \mathrm{mg} / \mathrm{kg}$ b.w., p.o. during 10 weeks. EOCz: volatile oil of $C$. zehntneri. ANT: anethole. Mean \pm S.E.M. ANOVA and followed by Bonferroni $\left({ }^{*} p<0.05 v\right.$ s. control $)$.

addition EOCZ and trans-anethole, did not alter either the relative or the absolute weight of most of the organs analyzed, except for the relative weight of kidney, which was increased by $11 \%$ (Table 2). Clinical abnormalities that would suggest toxicity were not observed, such as external and eye lesions, changes in hair color and distribution (data not shown).

\section{Biochemical and hematological parameters of rats treated with $E O C z$}

The treatment with $\mathrm{EOC} z$, as with trans-anethole, did not induce alterations in the function biomarkers of pancreas ( $\alpha$-amylase and lipase), kidney (urea and creatinine), heart (CK and CK-MB) and liver (ALT, alanine aminotransferase; AST, aspartate aminotransferase; LDH, lactate dehydrogenase; AP, alkaline phosphatase; TB, total bilirubin; DB, direct bilirubin; IB, indirect bilirubin; TP, total protein). However, EOCz and trans-anethole increased in 7 and 4 fold, respectively, the serum biomarker of liver function (gamma
Table 2

Absolute and relative organs weight of rats after 10 week-treatment with volatile oil of Croton zehntneri or anethole.

\begin{tabular}{|c|c|c|c|}
\hline \multirow[t]{2}{*}{ Parameters } & \multicolumn{3}{|c|}{ Treatment } \\
\hline & Control & $\mathrm{EOCz}$ & Anethole \\
\hline Body mass(g) & a $379 \pm 6.6$ & $364 \pm 7.97$ & $371 \pm 10.14$ \\
\hline \multicolumn{4}{|l|}{ Liver } \\
\hline Absolute (g) & $12.356 \pm 0.486$ & $12.923 \pm 0.512$ & $12.661 \pm 0.371$ \\
\hline Relative (mg/g) & $32.540 \pm 0.144$ & $35.590 \pm 0.145$ & $34.190 \pm 0.050$ \\
\hline \multicolumn{4}{|l|}{ Heart } \\
\hline Absolute (g) & $1.051 \pm 0.046$ & $1.016 \pm 0.036$ & $1.054 \pm 0.045$ \\
\hline Relative (mg/g) & $2.770 \pm 0.011$ & $2.810 \pm 0.013$ & $2.850 \pm 0.012$ \\
\hline \multicolumn{4}{|l|}{ Ileum } \\
\hline Absolute (g) & $9.147 \pm 0.203$ & $8.481 \pm 0.325$ & $8.924 \pm 0.480$ \\
\hline Relative (mg/g) & $24.180 \pm 0.075$ & $23.340 \pm 0.088$ & $23.790 \pm 0.105$ \\
\hline \multicolumn{4}{|l|}{ Empty stomach } \\
\hline Absolute (g) & $1.762 \pm 0.055$ & $1.799 \pm 0.050$ & $1.797 \pm 0.045$ \\
\hline Relative (mg/g) & $4.660 \pm 0.018$ & $5.030 \pm 0.013$ & $4.870 \pm 0.014$ \\
\hline \multicolumn{4}{|l|}{ Full stomach } \\
\hline Absolute (g) & $4.539 \pm 0.467$ & $4.773 \pm 0.656$ & $4.435 \pm 0.473$ \\
\hline Relative (mg/g) & $11.000 \pm 0.089$ & $13.210 \pm 0.195$ & $11.900 \pm 0.113$ \\
\hline \multicolumn{4}{|l|}{ Kidney } \\
\hline Absolute (g) & $1.101 \pm 0.055$ & $1.165 \pm 0.022$ & $1.218 \pm 0.039$ \\
\hline Relative (mg/g) & $2.890 \pm 0.015$ & $3.210 \pm 0.005^{\mathrm{b}}$ & $3.320 \pm 0.016^{b}$ \\
\hline \multicolumn{4}{|l|}{ Pancreas } \\
\hline Absolute (g) & $1.366 \pm 0.089$ & $1.364 \pm 0.085$ & $1.380 \pm 0.098$ \\
\hline Relative (mg/g) & $3.600 \pm 0.023$ & $3.730 \pm 0.019$ & $3.770 \pm 0.031$ \\
\hline \multicolumn{4}{|l|}{ Spleen } \\
\hline Absolute (g) & $0.755 \pm 0.029$ & $0.735 \pm 0.050$ & $0.719 \pm 0.022$ \\
\hline Relative (mg/g) & $1.990 \pm 0.008$ & $2.000 \pm 0.023$ & $1.950 \pm 0.006$ \\
\hline \multicolumn{4}{|l|}{ Lung } \\
\hline Absolute (g) & $1.522 \pm 0.083$ & $1.517 \pm 0.054$ & $1.522 \pm 0.054$ \\
\hline Relative (mg/g) & $3.850 \pm 0.014$ & $4.180 \pm 0.017$ & $4.120 \pm 0.015$ \\
\hline \multicolumn{4}{|l|}{ Adrenal gland } \\
\hline Absolute (g) & $0.163 \pm 0.022$ & $0.173 \pm 0.066$ & $0.122 \pm 0.019$ \\
\hline Relative(mg/g) & $0.427 \pm 0.006$ & $0.482 \pm 0.0184$ & $0.551 \pm 0.016$ \\
\hline \multicolumn{4}{|l|}{ Brain } \\
\hline Absolute (g) & $1.651 \pm 0.074$ & $1.740 \pm 0.066$ & $1.730 \pm 0.045$ \\
\hline Relative (mg/g) & $4.360 \pm 0.021$ & $4.790 \pm 0.018$ & $4.700 \pm 0.017$ \\
\hline
\end{tabular}

a Mean \pm S.E.M. $(n=10)$.

b $p \leq 0.05 v$ s. control (ANOVA and Student's t-test).

glutamyl transpeptidase (GAMA-GT), but only EOCz, decreased uric acid, the serum biomarker of kidney function (Table 3). The hematological parameters were unaltered by EOCz or trans-anethole (Table 4), being the erythrocytes normocytic and normochromic (data not shown).

\section{Histological pattern of organs from rats treated with EOCZ}

Some histological alterations were observed in the following organs: liver - discrete hydroponic degeneration and vascular congestion; lung, stomach and duodenum - discrete inflammatory infiltration (laminas not shown); adrenal gland cortex-discrete 
Table 3

Biochemical blood parameters of rats after 10 week-treatment with volatile oil of Croton zehntneri or anethole.

\begin{tabular}{lccc}
\hline Parameters & \multicolumn{3}{c}{ Treatment } \\
\cline { 2 - 4 } & Control & EOCz & Anethole \\
\hline ALT $(\mathrm{U} / \mathrm{l})$ & $62.00 \pm 3.26$ & $66.44 \pm 6.15$ & $70.89 \pm 4.23$ \\
AST $(\mathrm{U} / \mathrm{l})$ & $190.00 \pm 18.00$ & $230.00 \pm 42.00$ & $230.00 \pm 35.00$ \\
LDH $(\mathrm{U} / \mathrm{l})$ & $4034.00 \pm 185.00$ & $4097.00 \pm 179.00$ & $4010.00 \pm 236.00$ \\
AP $(\mathrm{U} / \mathrm{l})$ & $225.00 \pm 15.00$ & $204.00 \pm 10.00$ & $192.00 \pm 14.00$ \\
GAMA-GT (U/l) & $0.30 \pm 0.15$ & $2.10 \pm 0.27^{\mathrm{b}}$ & $1.33 \pm 0.16^{\mathrm{a}}$ \\
TB $(\mathrm{mg} / \mathrm{dl})$ & $0.33 \pm 0.06$ & $0.24 \pm 0.04$ & $0.25 \pm 0.03$ \\
DB $(\mathrm{mg} / \mathrm{dl})$ & $0.03 \pm 0.01$ & $0.03 \pm 0.004$ & $0.03 \pm 0.005$ \\
IB $(\mathrm{mg} / \mathrm{dl})$ & $0.27 \pm 0.06$ & $0.30 \pm 0.08$ & $0.22 \pm 0.03$ \\
TP $(\mathrm{mg} / \mathrm{dl})$ & $6.56 \pm 0.14$ & $6.67 \pm 0.11$ & $6.62 \pm 0.13$ \\
Albumin $(\mathrm{mg} / \mathrm{dl})$ & $3.15 \pm 0.05$ & $3.30 \pm 0.06$ & $3.31 \pm 0.05$ \\
Globulin (mg/dl) & $3.41 \pm 0.10$ & $3.30 \pm 0.06$ & $3.31 \pm 0.05$ \\
Urea (mg/dl) & $54.00 \pm 2.86$ & $49.00 \pm 1.22$ & $53.00 \pm 53.00$ \\
Creatinine (mg/dl) & $0.44 \pm 0.04$ & $0.40 \pm 0.02$ & $0.45 \pm 0.02$ \\
Uric acid (mg/dl) & $1.17 \pm 0.19$ & $0.73 \pm 0.05^{\mathrm{a}}$ & $0.91 \pm 0.08$ \\
CK-total $(\mathrm{mg} / \mathrm{dl})$ & $1820.00 \pm 319.00$ & $1956.00 \pm 361.00$ & $2501.00 \pm 502.00$ \\
CK-MB (mg/dl) & $1890.00 \pm 262.00$ & $1915.00 \pm 150.00$ & $1795.00 \pm 140.00$ \\
Amylase (U/l) & $1206.00 \pm 62.00$ & $1227.00 \pm 47.00$ & $1185.00 \pm 39.00$ \\
Lipase (U/l) & $11.00 \pm 0.31$ & $12.00 \pm 1.41$ & $11.00 \pm 0.39$ \\
\hline ALT
\end{tabular}

ALT, alanine aminotransferase; AST, aspartate aminotransferase; LDH, lactate dehydrogenase; AP, alcaline phosphatase; GAMMA-GT, gamma glutamyl transpeptidase; $\mathrm{TB}$, total bilirubin; $\mathrm{DB}$, directbilirubin; IB, indirect bilirubin; TP, total protein: $\mathrm{CK}-$ Total, total creatine phosphokinase; $\mathrm{CK}-\mathrm{MB}$, creatine phosphokinase MB fraction. Mean \pm S.E.M.

a $p \leq 0.05$ vs. control (ANOVA and Student's $t$-test).

b $p \leq 0.001 v s$. control (ANOVA and Student's $t$-test).

vascular congestion; spleen - discrete hemorrhage and inflammatory cell infiltrate; cerebral cortex - moderate hemorrhage and vascular congestion; heart - moderate lymphohistiocytic inflammatory cell infiltrate (Fig. 2).
Table 4

Hematological parameters of rats after 10 week-treatment with volatile oil of Croton zehntneri or anethole.

\begin{tabular}{|c|c|c|c|}
\hline \multirow[t]{2}{*}{ Parameters } & \multicolumn{3}{|c|}{ Treatment } \\
\hline & Control & $\mathrm{EOCz}$ & Anethole \\
\hline Erythrocytes $\times 10^{6}$ & $8.40 \pm 0.14$ & $8.39 \pm 0.32$ & $8.24 \pm 0.28$ \\
\hline $\mathrm{Hgb}(\mathrm{g} / \mathrm{dl})$ & $15.97 \pm 0.33$ & $16.01 \pm 0.79$ & $16.02 \pm 0.51$ \\
\hline $\mathrm{HCT}(\%)$ & $50.24 \pm 1.03$ & $50.16 \pm 2.21$ & $50.37 \pm 1.76$ \\
\hline $\operatorname{MCV}\left(\mu \mathrm{m}^{3}\right)$ & $59.78 \pm 0.28$ & $59.78 \pm 0.40$ & $59.78 \pm 0.52$ \\
\hline $\mathrm{MCH}(\mathrm{pg})$ & $19.04 \pm 0.09$ & $19.02 \pm 0.29$ & $19.09 \pm 0.18$ \\
\hline $\mathrm{MCHC}(\mathrm{g} / \mathrm{dl})$ & $31.84 \pm 0.10$ & $31.89 \pm 0.37$ & $31.89 \pm 0.20$ \\
\hline RDW (\%) & $14.00 \pm 0.19$ & $14.60 \pm 0.21$ & $14.79 \pm 0.26$ \\
\hline Leukocytes $/ \mathrm{mm}^{3}$ & $7.68 \pm 0.62$ & $8.31 \pm 0.53$ & $8.24 \pm 0.75$ \\
\hline Neutrophils (\%) & $11.09 \pm 0.78$ & $11.12 \pm 0.85$ & $9.58 \pm 0.71$ \\
\hline Lymphocytes (\%) & $86.74 \pm 0.99$ & $86.18 \pm 1.29$ & $88.27 \pm 1.12$ \\
\hline Monocytes (\%) & $0.80 \pm 0.19$ & $0.70 \pm 0.11$ & $0.54 \pm 0.09$ \\
\hline Eosinophils (\%) & $0.80 \pm 0.15$ & $0.73 \pm 0.23$ & $0.99 \pm 0.59$ \\
\hline Basophils (\%) & $0.57 \pm 0.06$ & $0.90 \pm 0.30$ & $0.62 \pm 0.12$ \\
\hline Platelets $\times 10^{3} \mathrm{~mm}^{3}$ & $596.00 \pm 45.16$ & $541.11 \pm 62.02$ & $519.00 \pm 51.78$ \\
\hline
\end{tabular}

Hgb, hemoglobin; HCT, hematocrit; MCV, mean corpuscular volume; $\mathrm{MCH}$, mean corpuscular hemoglobin; MCHC, mean corpuscular hemoglobin concentration; RDW, red cell distribution width. Mean \pm S.E.M.

${ }^{\mathrm{a}} p \leq 0.05$ vs. control (ANOVA and Student-Newman-Keuls Method).

\section{Discussion}

The investigation of $\mathrm{EOCz}$ (p.o.) systemic toxicity in rats, assessed by several parameters (survival, water and food consumption, body mass, absolute and relative organs weight, blood biochemical dosage, hemogram and organs morphology), demonstrated that all animals survived and no major toxicity was observed in most of the organs analyzed.
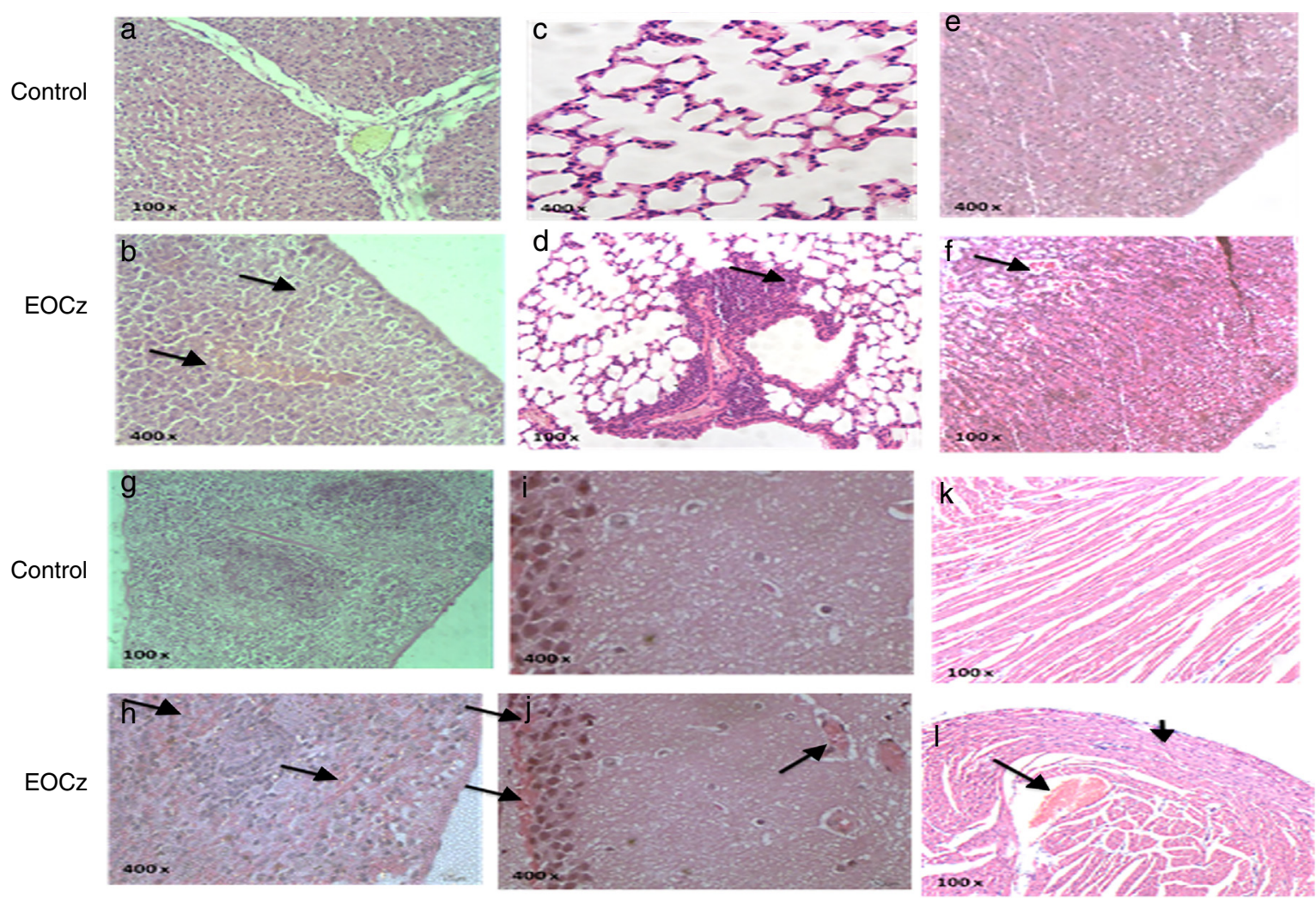

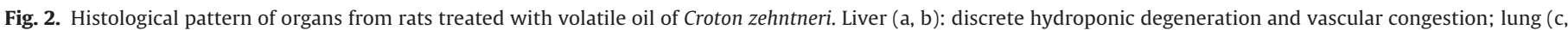

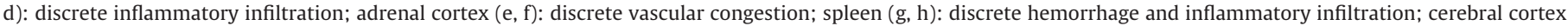

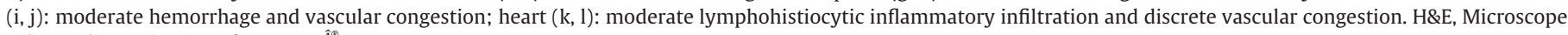
Nikon Eclipse Nis, Nis Software $4.0^{\hat{A}^{\circledast}}$. 
Volatile oil reduced the animal weight gain and food intake after eight weeks of treatment, an effect that was also elicited by the reference drug trans-anethole, the main constituent of EOCz (Le Bourhis and Soenen, 1973). In accordance, other studies revealed that trans-anethole $(600-1500 \mathrm{mg} / \mathrm{kg})$ reduces the animal weight gain (Newberne et al., 1999). This data suggest that the reduction in the animal weight gain and in food intake caused by EOCz could be assigned to trans-anethole.

Treatment with EOCz or trans-anethole did not change pancreatic or cardiac function, since no alterations were observed in the serum concentration of $\alpha$-amylase, lipase, CK or CK-MB. Although it is difficult to correlate enzyme activity with cardiac injury, as most enzymes are not confined into specific organs, CK and CK$\mathrm{MB}$ are very useful to indicate heart damage. In respect to kidney, EOCz and trans-anethole did not alter plasma levels of urea and creatinine. However, EOCz caused significant reduction in uric acid, the main product of purine metabolism, that is excreted in the urine and its increase in plasma concentrations is usually associated with renal dysfunctions. Moreover, the hematological profile was unaltered by EOCz, but it was by trans-anethole, that caused slight increase in RDW (red distribution width), a parameter that numerically represents variations of the volume of red blood cells. High RDW values may indicate changes in erythrocyte maturation, however, this alteration isolated, not associated to other hematological changes, does not indicate toxic effect, although may be a potential prognostic marker in patients with cancer (Hu et al., 2017), as observed in this study.

In mammals, the major constituent of EOCz, trans-anethole, is completely metabolized in the liver, conjugated and excreted in the urine. Its detoxification occurs via three main routes ( $\omega$ oxidation, $o$-demethylation and epoxidation) that vary according to specie, sex, dose and duration. Epoxidation, the minority route (3-8.8\%) provides the stable metabolite trans-anethole epoxide (AE), by which the daily production of $\mathrm{AE}$ during a period longer than 90 days and doses higher than $120 \mathrm{mg} / \mathrm{kg}$ induces hepatotoxic effects, such as cellular hypertrophy, inflammatory infiltrate, sinusoidal dilation, hyperplasia and carcinoma (Newberne et al., 1999). Despite of the dose used in this study $(250 \mathrm{mg} / \mathrm{kg}$ ), either greater than or at the higher end of the range for effective pharmacological activity, we believe that very likely no functional important hepatotoxic effect was observed, as we discuss below, suggesting no liver accumulation of $\mathrm{AE}$ metabolite. In the present study both $\mathrm{EOCZ}$ and trans-anethole did not alter hepatic function markers (ALT, AST, alkaline phosphatase, lactate dehydrogenase-LDH, total protein) or caused important alteration in the liver histology. In addition, no changes in the main bile pigment (total, direct and indirect bilirubin) were observed, indicating that neither EOCz nor trans-anethole interfere with the conjugation of bile salts or with their elimination by the biliary ducts.

Dealing more specifically with the subject of hepatic toxicity, it is important to consider and to analyze the fact that the animals treated with $\mathrm{EOCz}$ or trans-anethole exhibited increased levels of GAMA-GT. This enzyme is of clinical importance and considered a biomarker of high sensitivity to hepatobiliary injury, being associated with liver and bile ducts diseases (Pratt and Kaplan, 2000; Dufour et al., 2000). However, the increased levels of GAMA-GT here observed, as related to hepatic toxicity, should be interpreted with caution. First, the range of Gamma-GT normal values is very large (in humans is $\leq 38$ for women and $\leq 55$ for men) and the value obtained in presence of anethole and EOC $z$ is very close to control in other experimental studies in rats (Abdelhalim et al., 2018; Salama et al., 2018). Second, as mentioned above, other blood biochemical biomarkers of liver toxicity were not affected. Third, an increase in GAMA-GT might reflect a minor toxicity of other organ, in our study the kidney, perhaps, which is increased in weight (see Ward, 1975; Kwiatkowska et al., 2014). Fourth, the literature describes that both trans-anethole and EOCz exert hepatoprotective effect in rats via reduction of ALT and AST in the model of acute hepatotoxicity induced by acetaminophen (Lima et al., 2008; da Rocha et al., 2016). Fifth, GAMA-GT has low specificity since it can be altered by the use of drugs and alcohol or by various pathological conditions, such as cardiovascular diseases, fatty liver (Yokoyama et al., 2000; Nomura et al., 1986), obesity and diabetes type 2 (Perry et al., 1998; Nakanishi et al., 2004). Thus, despite the fact that the increase in GAMMA-GT unauthorizes ruling out OECz and anethole hepatotoxicity, the chance of occurrence or, should it occur, of functional significance of this toxicity is likely to be minimum, since hepatocellular injuries induced by certain drugs may be translated to an increase in serum concentrations of AST, ALT and other signs of hepatic injury (Farghali et al., 2016), which were not observed in this study. Although EOCz had caused discrete morphological alterations in some organs and blood biochemical modifications, it did not induce major morphological and functional changes. Accordingly, the discrete vascular congestion observed in the liver may be analyzed following this line of reasoning.

In conclusion, the sub-acute per oral treatment with EOCz and anethole, no longer than ten weeks in rats offers small toxicity at doses below $250 \mathrm{mg} / \mathrm{kg}$, and have a potentiality for therapeutic use, provided that the analysis risk/benefit endorse that.

\section{Ethical disclosures}

Protection of human and animal subjects. The authors declare that the procedures followed were in accordance with the regulations of the relevant clinical research ethics committee and with those of the Code of Ethics of the World Medical Association (Declaration of Helsinki).

Confidentiality of data. The authors declare that no patient data appear in this article.

Right to privacy and informed consent. The authors declare that no patient data appear in this article.

\section{Authors contributions}

MVAPR, KAO, YAGV, ECS and ELP conducted animal experiments; KSSA conducted the EOCz extraction; MVAPR and ACO performed the hematologic and biochemical analysis; JSAME performed morphological analysis; ANCS, LRLD and JHLC supplied critical input to experimental design and data interpretation; and FWFS provided statistical analysis and interpretation; ANCS, AMSA and JHLC were responsible for writing the manuscript. All authors have read and approved the submission of the manuscript.

\section{Funding}

The authors thank CNPq, FUNCAP and CAPES for funding and granting scholarships to students and to UniChristus for the animals supply.

\section{Conflicts of interest}

The authors declare no conflicts of interest.

\section{Acknowledgments}

This research was supported by CNPq, CAPES, Fundação de Amparo ao Desenvolvimento Científico e Tecnológico do Estado do Ceará and Financiadora de Estudos e Projetos and UniChristus. 


\section{References}

Abdelhalim, M.A.K., Moussa, S.A.A., Qaid, H.A.Y., 2018. The protective role of quercetin and arginine on gold nanoparticles induced hepatotoxicity in rats. Int. J. Nanomed. 11, 2821-2825.

Albuquerque, A.A.C., Sorenson, A.L., Leal-Cardoso, J.H., 1995. Effects of essential oil of Croton zehntneri, and of anethole and estragole on skeletal muscles. J. Ethnopharmacol. 49, 41-49.

Andrade, T.C., De Lima, S.G., Freitas, R.M., Rocha, M.S., Islam, T., Da Silva, T.G., Militão, G.C., 2015. Isolation, characterization and evaluation of antimicrobial and cytotoxic activity of estragole, obtained from the essential oil of Croton zehntneri (Euphorbiaceae). An. Acad. Bras. Cienc. 87, 173-182.

Batatinha, M.J., Souza-Spinosa, H., Bernardi, M.M., 1995. Croton zehntneri: possible central nervous system effects of the essential oil in rodents. J. Ethnopharmacol. 4, 53-57.

Camurça-Vasconcelos, A.L., Bevilaqua, C.M., Morais, S.M., Maciel, M.V., Costa, C.T., Macedo, I.T., Oliveira, L.M., Braga, R.R., Silva, R.A., Vieira, L.S., 2007. Anthelmintic activity of Croton zehntneri and Lippia sidoides essential oils. Vet. Parasitol. 148, 288-294.

Cavalcanti, J.M., Leal-Cardoso, J.H., Diniz, L.R., Portella, V.G., Costa, C.O., Linard, C.F., Alves, K., Rocha, M.V., Lima, C., Cecatto, C., Coelho-de-Souza, V.M.A.N., 2012. The essential oil of Croton zehntneri and trans-anethole improves cutaneous wound healing. J. Ethnopharmacol. 144, 240-247.

Chen, C.H., de Graffenried, L.A., 2012. Anethole suppressed cell survival and induced apoptosis in human breast cancer cells independent of estrogen receptor status. Phytomedicine 19, 763-767.

Choo, E.J., Rhee, Y.H., Jeong, S.J., Lee, H.J., Kim, H.S., Ko, H.S., Kim, J.H., Kwon, T.R., Jung, J.H., Kim, J.H., Lee, H.J., Lee, E.O., Kim, D.K., Chen, C.Y., Kim, S.H., 2011. Anethole exerts antimetastatic activity via inhibition of matrix metalloproteinase $2 / 9$ and AKT/mitogen-activated kinase/nuclear factor kappa B signaling pathways. Biol. Pharm. Bull. 34, 41-46.

Coelho-de-Souza, A.N., Barata, E.L., Magalhães, P.J.C., Lima, C.C., Leal-Cardoso, J.H., 1997. Effects of the essential oil of Croton zenhtneri and its constituents estragole on intestinal smooth muscle. Phytother. Res. 11, 299-304.

Coelho-de-Souza, A.N., Criddle, D.N., Leal-Cardoso, J.H., 1998. Selective and modulatory effects of the essential oil of Croton zenthneri on isolated smooth muscle preparations of the guinea pig. Phytother. Res. 12, 189-194.

Coelho-de-Souza, A.N., Lahlou, S., Barreto, J.E., Yum, M.E., Oliveira, A.C., Oliveira, H.D., Celedônio, N.R., Feitosa, R.G., Duarte, G.P., Santos, C.F., de Albuquerque, A.A., LealCardoso, J.H., 2013. Essential oil of Croton zehntneri and its major constituent anethole display gastroprotective effect by increasing the surface mucous layer. Fund. Clin. Pharmacol. 27, 288-298.

Craveiro, A.A., Andrade, C.H.S., Matos, F.J.A., Alencar, J.W., 1977. Óleos essenciais de canelas silvestres regionais. Cienc. Cult. 29, 445.

da Rocha, B.A., Ritter, A.M., Ames, F.Q., Gonçalves, O.H., Leimann, F.V., Bracht, L., Natali, M.R., Cuman, R.K., Bersani-Amado, C.A., 2016. Acetaminophen-induced hepatotoxicity: preventive effect of trans anethole. Biomed. Pharmacother. 86, 213-220.

de Siqueira, R.J.B., Magalhães, P.J.C., Leal-Cardoso, J.H., Duarte, G.P., Lahlou, S., 2006. Cardiovascular effects of the essential oil of Croton zehntneri leaves and its main constituents in rats. Life Sci. 78, 2365-2372.

Dufour, D.R., Lott, J.A., Nolte, F.S., Gretch, D.R., Koff, R.S., Seeff, L.B., 2000. Diagnosis and monitoring of hepatic injury. I. Performance characteristics of laboratory tests. Clin. Chem. 46, 2027-2049.

Farghali, H., Kgalalelo, K.M., Wojnarová, L. Kutinová, C.N., 2016. In vitro and in vivo experimental hepatotoxic models in liver research: applications to the assessment of potential hepatoprotective drugs. Physiol. Res. 65, S417-S425.

Fontenelle, R.O., Morais, S.M., Brito, E.H., Brilhante, R.S., Cordeiro, R.A., Nascimento N.R., Kerntopf, M.R., Sidrim, J.J., Rocha, M.F., 2008. Antifungal activity of essential oils of Croton species from the Brazilian Caatinga biome. J. Appl. Microbiol. 104, 1383-1390.

Galicka, A., Krętowski, R., Nazaruk, J., Cechowska-Pasko, M., 2014. Anethole prevents hydrogen peroxide-induced apoptosis and collagen metabolism alterations in human skin fibroblasts. Mol. Cell. Biochem. 394, 217-224.
Hu, L., Li, M., Ding, Y., Pu, L., Liu, J., Xie, J., Cabanero, M., Li, J., Xiang, R., Xiong, S., 2017. Prognostic value of RDW in cancers: a systematic review and meta-analysis. Oncotarget 8, 16027-16035.

Kwiatkowska, E., Domański, L., Bober, J., Safranow, K., Pawlik, A., Sebastian Kwiatkowsk, S., Ciechanowski, K., 2014. Gamma-glutamyl transpeptidase as the marker of kidney graft function. Adv. Clin. Exp. Med. 23, 947-952.

Lazarini, C.A., Uerna, A.H., Brandão, G.M.S., Guimarães, A.P.C., Bernardi, M.M., 2000 Croton zehntneri essential oil: effects on behavioral models related to depression and anxiety. Phytomedicine 7, 477-481.

Le Bourhis, B., Soenen, A.M., 1973. Psychotropic action of some aromatic substances used in food. Food. Cosmet. Toxicol. 11, 1-9.

Leal-Cardoso, J.H., Fonteles, M.C., 1999. Pharmacological effects of essential oils of plants of the northeast of Brazil. An. Acad. Bras. Cienc. 71, 207-213.

Lima, F.C., Sousa, D.F., Ferreira, J.M., Júnior, R.C.P.L., Tomé, A.R., Leal-Cardoso, J.H., Queiroz, M.G.R., Campos, A.R., 2008. Croton zehntneri essential oil prevents acetaminophen-induced acute hepatotoxicity in mice. Rec. Nat. Prod. 2, $135-140$.

Morais, S.M., Cavalcanti, E.S., Bertini, L.M., Oliveira, C.L., Rodrigues, J.R., Cardoso, J.H. 2006. Larvicidal activity of essential oils from Brazilian Croton species against Aedes aegypti L. J. Am. Mosq. Contr. 22, 161-164.

Nakanishi, N., Suzuki, K., Tatara, K., 2004. Serum gamma-glutamyl transferase and risk of metabolic syndrome and type 2 diabetes in middle-aged Japanese men. Diabetes Care 27, 1427-1432.

Newberne, P., Smith, R.L., Doull, J., Goodman, J.I., Munro, I.C., Portoghese, P.S., Wagner, B.M., Weil, C.S., Woods, L.A., Adams, T.B., Lucas, C.D., Ford, R.A., 1999. The Fema Gras assessment of trans-anethole used as a flavouring substance Food. Chem. Toxicol. 37, 789-811.

Nomura, F., Ohnishi, K., Satomura, Y., Ohtsuki, T., Fukunaga, K., Honda, M., Ema, M., Tohyama, T., Sugita, S., Saito, M., 1986. Liver function in moderate obesity study in 534 moderately obese subjects among 4613 male company employees. Int. J. Obesity 10, 349-354.

Oliveira, A.C., Leal-Cardoso, J.H., Santos, C.F., Morais, S.M., Coelho-De-Sousa, A.N 2001. Antinociceptive effects of the essencial oil of Croton zehntneri in mice. Braz. J. Med. Biol. Res. 34, 1471-1474.

Perry, I.J., Wannamethee, S.G., Shaper, A.G., 1998. Prospective study of serum gamma-glutamyl transferase and risk of NIDDM. Diabetes Care 21, $732-737$.

Ponte, E.L., Sousa, L.P., Rocha, M.V.A.P., Coelho-De-Sousa, A.N., Leal-Cardoso, J.H., Assreuy, A.M., 2012. Comparative study of the anti-edematogenic effects of anethole and estragole. Pharmacol. Rep. 64, 984-990.

Pratt, D.S., Kaplan, M.M., 2000. Evaluation of abnormal liver enzyme results in asymptomatic patients. New. Engl. J. Med. 342, 1266-1271.

Ritter, A.M.V., Hernandes, L., da Rocha, B.A., Estevão-Silva, C.F., Wisniewski-Rebecca, E.S., Cezar, J.D.S., Caparroz-Assef, S.M., Cuman, R.K.N., Bersani-Amado, C.A., 2017. Anethole reduces inflammation and joint damage in rats with adjuvant-induced arthritis. Inflamm. Res, 66, 725-737.

Salama, S.M., Ibrahim, I.A.A., Shahzad, N., Al-Ghamdi, S., Ayoub, N., AlRashdi, A.S., Abdulla, M.A., Salehen, N., Bilgen, M., 2018. Hepatoprotectivity of Panduratin A against liver damage: in vivo demonstration with a rat model of cirrhosis induced by thioacetamide. APMIS 126, 710-721.

Tognolini, M., Ballabeni, V., Bertoni, S., Bruni, R., Impicciatore, M., Barocelli, E., 2007. Protective effect of Foeniculum vulgare essential oil and anethole in an experimental model of thrombosis. Pharmacol. Res. 56, 254-260.

Ward, J.P., 1975. Urinary gamma-glutamyl transpeptidase, an indicator of renal ischaemic injury and homograft rejection. Brit. J. Urol. 47, 765-770.

Yokoyama, H., Hirose, H., Moriya, S., Saito, I., 2000. Significant correlation between insulin resistance and serum gamma glutamyl transpeptidase (gamma-GTP) activity in nondrinkers. Alcohol. Clin. Exp. Res. 26, 91-94.

Zahid, M.S., Awasthi, S.P., Asakura, M., Chatterjee, S., Hinenoya, A., Faruque, S.M., Yamasaki, S., 2015. Suppression of virulence of toxigenic Vibrio cholerae by anethole through the cyclic AMP (cAMP)-cAMP receptor protein signaling system. PLoS One 10, e0137529. 